\title{
Development of nanotechnology in high performance concrete
}

\begin{abstract}
Concrete is the most widely used building material all around the world which has been undergoing many changes aligned with technological advancement. The most recent available type of concrete is high performance concrete which is produced employing different admixtures both chemical and mineral to enhance mechanical and durability qualities. As sustainability emerged as an indispensable factor in concrete industry, many researchers targeted micro sized mineral admixtures such as silica fume, fly ash, rice husk ash, slag and so on in order to replace Portland cement which is known to be responsible for almost $7 \%$ of carbon dioxide emission into atmosphere. Recently, technology has made it easy for scientist to study nanoscale admixtures and their effect on structure of concrete. This paper reviews nanomaterials in cement composites and how they can improve different properties of concrete.
\end{abstract}

Keyword: Durability; High performance concrete; Mechanical property; Nanomaterials 